\title{
The Potential Mechanisms of Yinguoan Earth Fissure using 3D Seismic Exploration Data
}

\author{
J. Yu ${ }^{\text {a }}$ J.Q. Zhu ${ }^{\text {a }}$ X.L. Gong and Y. Yang ${ }^{\text {a }}$ \\ ${ }^{a}$ Key Laboratory of Earth Fissures Geological Disaster, Ministry of Land and Resources, Geological Survey \\ of Jiangsu Province, Nanjing, 210018, China \\ Email:yyun1985@gmail.com
}

\begin{abstract}
Earth fissures with unexpected emergence occur in different regions of the world, especially in $\mathrm{Su}-\mathrm{Xi}$-Chang area, Jiangsu Province, China. In this area, earth fissure features attributed to human activities such as excessive groundwater withdrawal and coupled with distinctive geological structures are widely developed, and Yinguoan earth fissure is a recognized example around this area. Here, the high-resolution 3D seismic exploration technology is proposed for Yinguoan earth fissure formation. The 3D seismic exploration data provide interpreters with the ability to map structures and stratigraphic features (such as viscoelastic strata, buried bedrock hill and aquifer thickness variation) in 3D detail. Furthermore, the correlation between the earth fissure and the above three intrinsic factors are semi-quantitatively analyzed. The results demonstrate the potential of the 3D seismic exploration for investigating sites where earth fissures exist and offer a prerequisite to physical and numerical modeling for predicting sensitive area of earth fissure.
\end{abstract}

Keywords: Earth fissure; 3D seismic data; visco-elastic strata; buried bedrock hill; aquifer thickness variation; Yinguoan, Wuxi City 


\section{INTRODUCTION}

Earth fissures are widespread geohazard in Su-Xi-Chang area, Jiangsu Province, China, causing environmental and economic impacts. A series of investigation, such as geographical exploration, geological drilling have been conducted since Hetang earth fissure within the Su-Xi-Chang area being first reported in 1995. The investigation has found that there is a dramatic change in the Quaternary soil profile in case of a steep contact of Quaternary with the ancient buried bedrock hill in this area and recognized the causative factors as the human activities such as excessive groundwater withdrawal and coupled with distinctive geological structures (e.g. Zhu et al., 1993; Gao et al., 1997; Hu and Wu, 1998). Yinguoan earth fissure is the recognized examples around this area. The earth fissures have resulted in damage to a variety of buildings, houses and cement roads along the fissure zone and adversely affected the local economic development (Figure 1).
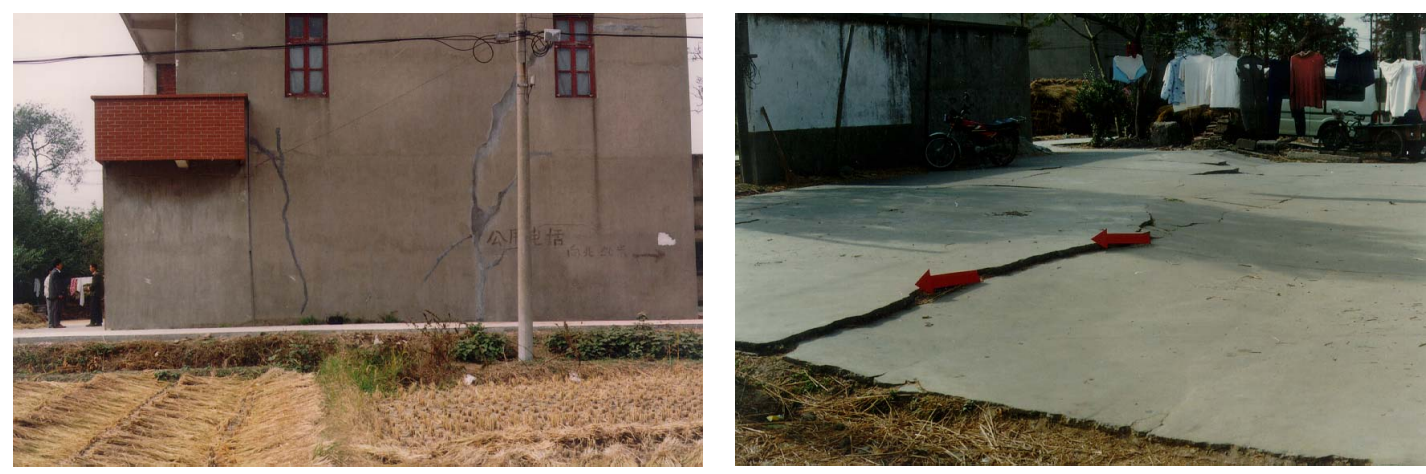

Figure 1. Yinguoan earth fissure, Shitangwan Town, Wuxi City

Yinguoan earth fissure is located in Yinguoan, Shitangwan town, 12 kilometers from the northwest of Wuxi city (Figure 2). The study area is part of the alluvial plain of the Yangtze River Delta region with the ground elevation ranging from $1 \mathrm{~m}$ to $3 \mathrm{~m}$. Devonian quartz sandstone constitutes the basement of the basin. The quaternary is about $140 \mathrm{~m}$ thick, consisting of two confined aquifers. The second confined aquifer (Aquifer II) with the roof depth of $80 \mathrm{~m}$ and the thickness of $30 \mathrm{~m}$ to $50 \mathrm{~m}$ is the mainly exploited horizon in this region. The regional groundwater level depth in this unit is $87 \mathrm{~m}$, thus the aquifer is under non-pressure state. The geological survey shows that, the Yinguoan earth fissure occurred in 1991, and the main fracture belt extends nearly $2000 \mathrm{~m}$ and $50-150 \mathrm{~mm}$ width along the NE direction, having obvious tensile characteristics (e.g.

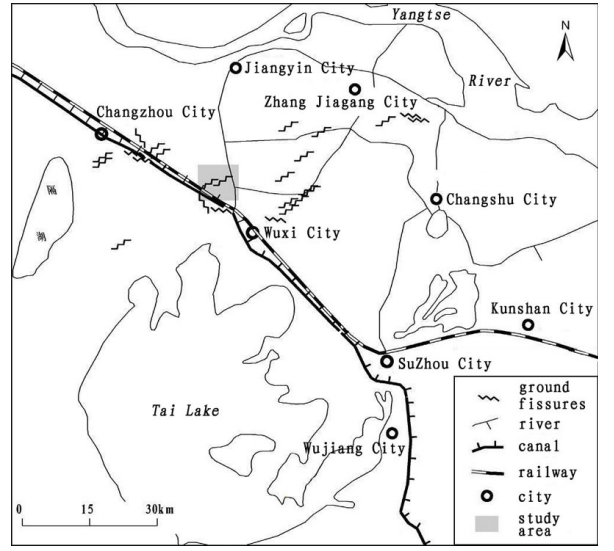

Figure 2. Location map of the study area Yu et al., 2004).

The previous work established a nondeterministic model which combines artificial neural network (ANN) with genetic algorithm (GA) to evaluate the nonlinear statistical relationship between the formation of earth fissure and its potential influencing factors, such as the discrepancies in the forms of bedrock hill, the structural differences in Quaternary sediment, the differential land subsidence and excessive groundwater extraction, and predict the hazard zoning in Su-Xi-Chang area (e.g. Jiao et al., 2006). In the previous work, the lithological information was based on the assumption that the bedrock was continuous and gained from the interpolation by only a few boreholes. The sketchy information had effect on the accuracy of the assessment results. Moreover, the ANN-GA predictive model exhibits a series of disadvantages including greater computation burden, requiring a large amount of pre-processed data, empirical nature of model development, resulting in uncertainty and risk in hazard assessment of earth fissures. To overcome the above inadequacy, this study presents the researches on its causative mechanism for the earth fissure occurrence using the 3D seismic exploration data.

The 3D seismic exploration, which can achieve completely continuous 3D geological information, has been widely applied in practice in recent years and has made visible impact in lithologic identification, fluid and fracture detection (e.g. Heggland, 1998; Li et al., 2003; Sargent and Goulty, 2009; Aldiss et al., 2012). The 
3D reflection seismic data provide interpreters with the ability to map structure and stratigraphic features in 3D detail with high Signal-to-Noise Ration (SNR), high resolution and high fidelity. The potentially factors to earth fissure, such as viscoelastic strata, buried bedrock hill and aquifer thickness variation, can be 3D interpreted detailedly. However, 3D seismic exploration is a totally new method of earth fissure detection in the beginning in China (e.g. Chen et al., 2004). This paper semi-quantitatively analyses three intrinsic factors using the medium of 3D seismic data and provides a prerequisite to physical and numerical modeling for predicting sensitive area of earth fissure.

\section{3D SEISMIC EXPLORATION}

The 3D seismic exploration in Yinguoan earth fissure, Wuxi City, implements measurements on blasting and field receiving points with the observation system of eight lines and eight shots. Sercel 408UL multichannel telemetry seismic instrument made in France is used for field data acquisition. The 3D seismic survey covers an area of $1.7 \mathrm{~km}^{2}$, yielding an effective control area of $0.88 \mathrm{~km}^{2}$ and 1040 physical points. The seismic lines are arranged as shown in Figure 3 and the detailed information about the 3D seismic survey was summarized by Yu et al. (2006).

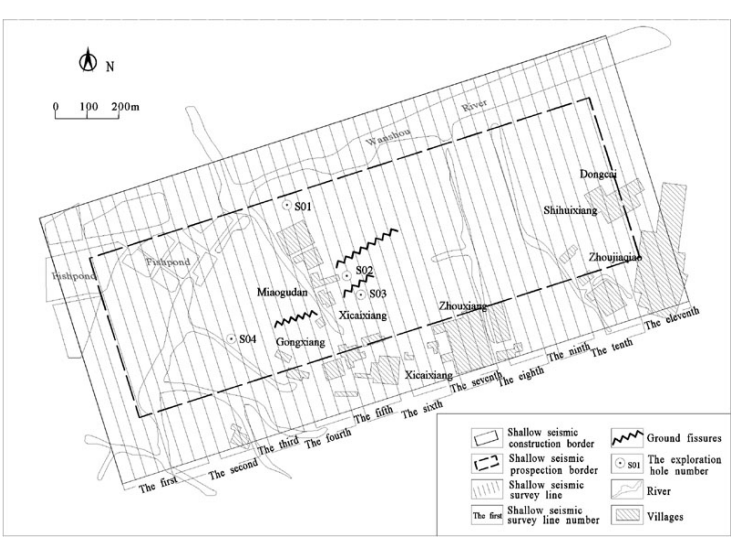

Figure 3. Map of measuring lines of 3D seismic exploration in Yinguoan area

\section{3D SEISMIC DATA PROCESSING}

To interpret the 3D seismic exploration data, geophysical prospecting technology, geological characteristics and practical experience are combined. Seismic velocity, logging data as well as measured depths of Aquifer II's roof and bedrock in Borehole S01 are used to derive reflection time corresponding to all geological horizons. Horizons of the same reflection time on seismic time section are considered as the same ones. By doing so, six layers including top/bottom interface of Aquifer II, bedrock surface are determined.

Theoretically, with the absence of any destruction by geological stress, the horizons yields complete, continuous and clearly structured shape on seismic time section. However, destructive geologic forces inducing earth fissure lead to changes in the original stratum structure and geophysical field. Figure 4 is the time section based on 3D seismic exploration data of Yinguoan earth fissure. It shows clearly the characteristics of faulted phase, energy conversion, amplitude variation of reflected wave as well as stratigraphic occurrence change

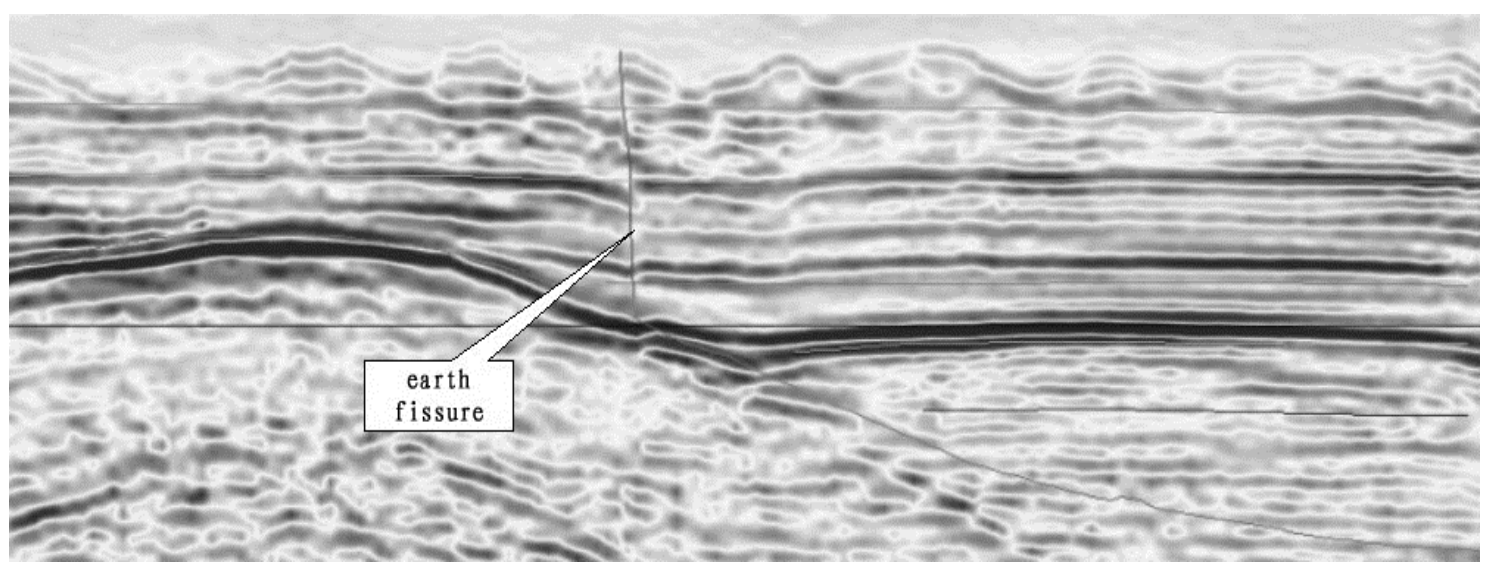

Figure 4. Characteristics of earth fissure on seismic time section in Yinguoan area 


\section{GENETIC ANALYSIS OF EARTH FISSURE}

\subsection{Viscoelastic Strata}

The quaternary of the Yinguoan area mainly consists of layers of marine, lagoon and river deposits, substantially containing clay, loamy clay, loam and sand. Based on the transverse wave velocity, $v_{s}$, longitudinal wave velocity, $v_{p}$, and logging data of the S01 exploration hole in Yinguoan area, the geophysical parameters of different lithological types can be obtained (Table 1).

Table 1. Geophysical parameters of the earth fissure in Yinguoan area

\begin{tabular}{|c|c|c|c|c|c|c|}
\hline Lithological Character & $\begin{array}{c}\text { S-wave velocity } \\
v_{s}(\mathrm{~m} / \mathrm{s})\end{array}$ & $\begin{array}{c}\text { P-wave velocity } \\
v_{p}(\mathrm{~m} / \mathrm{s})\end{array}$ & $\begin{array}{l}\text { Densities } \\
P\left(\mathrm{kN} / \mathrm{m}^{3}\right)\end{array}$ & $\begin{array}{c}\text { Poisson ratio } \\
\sigma\end{array}$ & $\begin{array}{c}\text { Shear Modulus } \\
\mu\left(\mathrm{kg} / \mathrm{cm}^{2}\right)\end{array}$ & $\begin{array}{c}\text { Elastic Modulus } \\
E\left(\mathrm{~kg} / \mathrm{cm}^{2}\right)\end{array}$ \\
\hline clay & 225 & 1675 & 19.91 & 0.4908 & 103 & 309 \\
\hline loam & 241 & 1693 & 19.52 & 0.4896 & 119 & 346 \\
\hline sandy loam & 263 & 1718 & 19.12 & 0.4880 & 138 & 482 \\
\hline sandy silt & 311 & 1755 & 19.32 & 0.4766 & 278 & 819 \\
\hline silt & 420 & 1760 & 20.20 & 0.4583 & 350 & 1408 \\
\hline Fine sand & 489 & 1762 & 19.81 & 0.4550 & 420 & 1703 \\
\hline medium sand & 495 & 1770 & 19.71 & 0.4535 & 478 & 1811 \\
\hline
\end{tabular}

As shown in Table 1, the physical property of the stratum in Yinguoan area has the following characteristics:

- The transverse wave velocity, $v_{s}$, of different lithological types are low, ranging among $225-495 \mathrm{~m} / \mathrm{s}$;

- The difference of formation densities is mild;

- The Poisson's ratio of the strata are large;

- The shear modulus of stratum are low, all lower than $500 \mathrm{~kg} / \mathrm{cm}^{2}$;

- The elastic modulus of the stratum are all lower than $1850 \mathrm{~kg} / \mathrm{cm}^{2}$

It can be concluded that the Quaternary strata in the area of Yinguoan earth fissure are less cemented. The stratum lacks the rigidly elastic characteristic, although it has the clear layer shape structure. Therefore, the sedimentary strata showing both the characteristics of elasticity and viscosity are called "viscoelastic strata" in elastic mechanics.

The longitudinal wave of the viscoelastic formation can be expressed using the Stokes equation (e.g. Yang et al., 1990):

$$
\begin{gathered}
\frac{\partial^{2}}{\partial x^{2}}\left(u+\frac{1}{\omega_{0}} \frac{\partial u}{\partial t}\right)=\frac{1}{v^{2}} \frac{\partial u^{2}}{\partial t^{2}} \\
1 / \omega_{0}=\left(\mu^{\prime \prime}+4 \mu^{\prime} / 3\right) / \rho v^{2}
\end{gathered}
$$

where $x$ is the Cartesian coordinate, $v$ is the longitudinal wave velocity, $\omega_{0}$ is the energy loss coefficient, $\mu^{\prime \prime}$ is the volume viscosity coefficient, $\mu^{\prime}$ is the shear viscosity coefficient.

In comparison with the classical wave equation, Equation 1 has one additional term of energy loss, $1 / \omega_{0}$, caused by internal friction. Therefore, the stress strain relationship of the viscoelastic strata is related to the strain history time rather than simply the instantaneous relation. As the elastic shear modulus, $\mu$, and the elastic modulus, $E$, are small, the stratum has low capacity in blocking shear strain and limited adaptability in the change of stress field, leading to low compressive strength. If the stratum is subject to strong external force, it is extremely easy to induce permanent deformation and form earth fissure which often gradually develops from deep to shallow. Therefore, viscoelastic formation is the most favorable combination factors to induce earth fissure. 


\subsection{Buried bedrock hill}

Based on the 3D seismic exploration data, the ancient buried hill, trending at NE-NEE direction, developed in the Yinguoan earth fissure site as shown in Figure 5. There exists great difference between the south and north sides of the buried hill; the depth gradient of north side is larger than south sides. The quaternary uplift area of the ancient buried hill becomes thinner significantly, less than $40 \mathrm{~m}$. In contrary, the thickness of Quaternary strata upon the south and north side increases gradually away from the ancient buried hill, and the depth is larger than $140 \mathrm{~m}$ in the northwest of Yinguoan area. The largest thickness difference is over $100 \mathrm{~m}$.

Since the thickness of the overlying Quaternary stratum above buried bedrock hill can be remarkably smaller than those elsewhere, the self-gravity is smaller than that of other area. In the process of long-term aquifers' release in the Quaternary stratum, this nonuniform self-gravity produces uneven tensile stress along the hillside strike orientation of the ancient buried hill. The maximum tensile stress locates at the area with the maximum angle of slope. Thus, the tensile stress acting on the Quaternary soil with such a dramatic change in the thickness generates the greatly differential land subsidence. The settlement can be calculated according to Physical field theory (e.g. Ricker 1979) as:

$$
S=F \times h\left[a /\left(1+e_{0}\right)+1 / E\right]
$$

where $S$ is the formation settlement, $F$ is the overlying strata force, which is proportional to the strata depth, $h$ is the overlying strata depth, $a$ is the compressibility of strata, $e_{0}$ is initial segment void ratio.

Equation 3 shows that the formation settlement is directly proportional to the force and the thickness of the overlying strata, but inversely proportional to the initial segment void ratio and elastic modulus of the overlying strata. Therefore, the formation settlement will be obviously restricted by shape of the ancient buried hill. Differential land subsidence is easy to induce ground failures or earth fissure.

As shown in Figure 5, the steepest slope angle near the north side of uplift area of buried hill, is near $60^{\circ}$, and the steepest slope angle in the north of Dongcai is near $40^{\circ}$, while the others are less than $30^{\circ}$ in the north area. In the northwest area where the ancient hill lies deeper, the slope angle is only about $10^{\circ}$. The earth fissure belts distribute along the steep northern slope of the buried hill where slope angle is within $40^{\circ}$ to $60^{\circ}$, leading to large tensile stresses. The component of formation settlement along the hillside of the ancient buried hill, $S_{g}$, is the sinusoidal function of slope angle of buried hill, $\theta$, and can be expressed as $S_{g}$ $=S \sin \theta$, where $S$ is the total settlement. We can conclude that the earth fissure is easy to occur at the place where the differential settlement generates maximal displacement along the hillside of ancient buried hill.

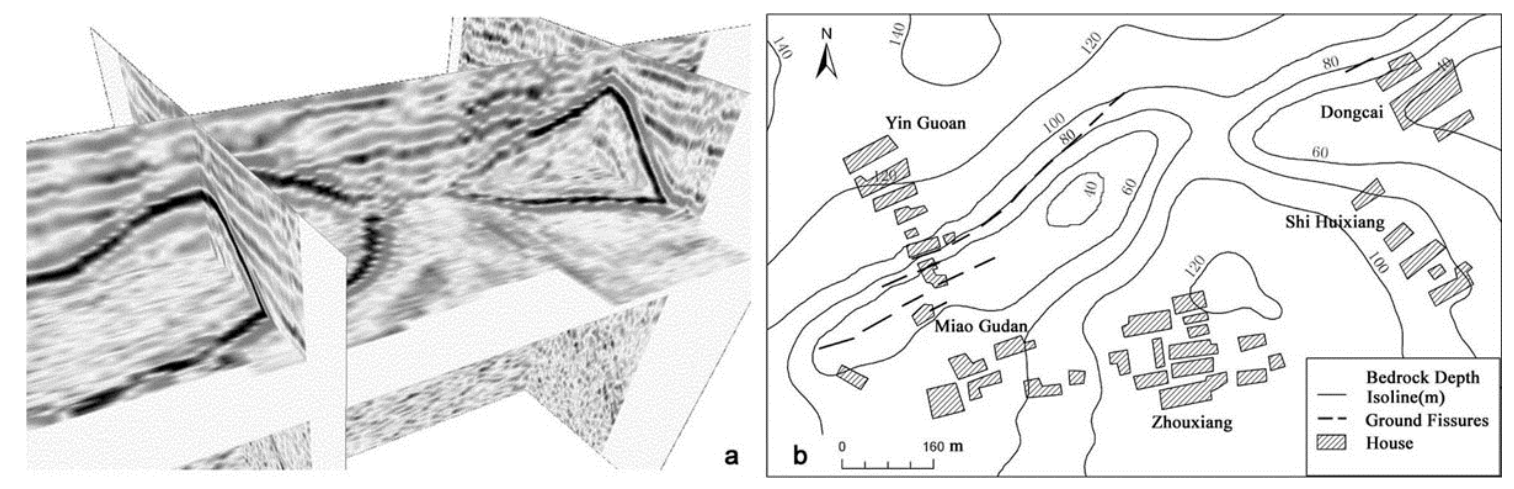

Figure 5. The shape (a) and depth contours map (b) of bedrock based on 3D seismic data

\subsection{Aquifer thickness variation}

Figure 6 is the combined map with the horizontal cross section of ancient buried hill $100 \mathrm{~m}$ below ground surface and the thickness contours of Aquifer II. It clearly reflects the variation of the water-bearing sand layer distributing along the north and south sides of buried hill. It can be seen that, firstly the thickness of sand layer is near $40 \mathrm{~m}$ nearby Zougang-Shihuigang zone in the south of Yinguoan area,

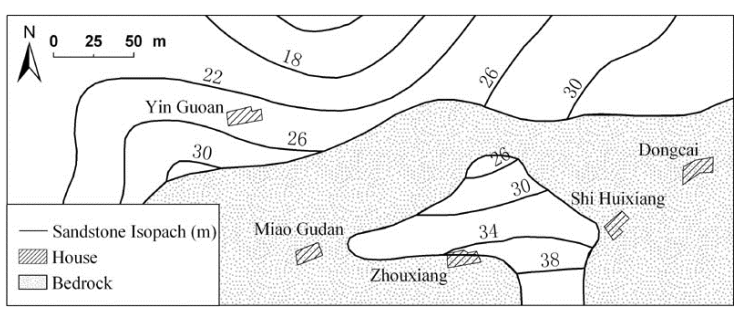

Figure 6. Thickness contour map of Aquifer II based on 3D seismic data 
whereas the thickness is less than $15 \mathrm{~m}$ in the north area. On the whole, the sand layer gradually becomes thinner from south to north. Secondly, the bedrock hill composed of Devonian quartz sandstone cuts through the sand aquifer.

In Yinguoan area, groundwater is mainly pumped from Aquifer II in the Quaternary. Aquifer II mainly belongs to the mid-Pleistocene fluvial sediments with the host lithohorizon of the gray medium-coarse sand, the fine sand with sandy loam. Within the confined aquifer itself there are severe disparities in thickness and water yield property. The total stress $p_{n}$ imposed in the aquifer at the normal direction based on the theory of elasticity can be expressed as the following (e.g. Wu et al., 2003),

$$
p_{n}=F h \cos \alpha /(a \times b)
$$

where $a$ is the direction angle of the force on the overlying strata, $a \times b$ is the cross-section area, and the others are the same as above.

Equation 4 shows that the total stress $p_{n}$ upon the water-bearing sand stratum is directly proportional to the overlying strata force, $F$, and the thickness of overlying sand aquifer, and is inversely proportional to the force area of cross-section, $a \times b$, Besides, it also depends on the stress direction. The thicker the aquifer water-bearing sand layer is, the larger external stress it can bear, while the thinner the aquifer is, the weaker external stress can tolerate. Obviously, the external stress tolerance in southern sand layer is generally stronger than that in the north.

Since the ancient buried hill cuts through the sand aquifer, the extremely weak zone is near where sand aquifer contacts bedrock hill. The layer undergoes discontinuity and fade-away. Therefore, the excessive groundwater withdrawal will first lead to total groundwater drainage in the thinnest aquifer with the lowest water-bearing capacity. The additional geologic stress caused by the decreasing groundwater level impacts most strongly on the contact area. As the stress exceeds stratum strength, a shear and/or tension crack occurs and the continuum and integrity is broken. As a result, the whole Yinguoan area will develop an uneven extensive stress field from south to north, and eventually cause northwards tensile earth fissure along the contact area of the sand layer and buried hill.

\section{CONCLUSION}

The earth fissure in Yinguoan, Wuxi is affected by internal and external factors. The external cause is the long-term excessive groundwater withdrawal. The internal cause is the specific geological conditions, such as viscoelastic strata, fluctuant form of the bedrock, and the spatial distribution of aquifer. The internal cause is the dominating factor responsible for differential land subsidence. The results demonstrate the potential of the 3D seismic exploration for investigating sites where earth fissures exist and offer a prerequisite to physical and numerical modeling for predicting sensitive area of earth fissure. There are some main points of this paper based on the analysis of 3D seismic data.

- The viscoelastic strata with low S-wave velocity less than $500 \mathrm{~m} / \mathrm{s}$, low elastic modulus less than 1800 $\mathrm{kg} / \mathrm{cm}^{2}$, low shear modulus which is smaller than $<500 \mathrm{~kg} / \mathrm{cm}^{2}$ and a big Poisson ratio more than 0.45 is a more favorable stratigraphic combination and important medium conditions for earth fissures.

- The buried hill less than $80 \mathrm{~m}$ deep whose surface changes violently is an intrinsic factor for earth fissures.

- Buried bedrock hill with the slope angle greater than $35^{\circ}$ is the site of the most concentrated tensile stress and also extremely fragile area to earth fissures.

- Thickness variation of sand aquifer determines self-gravity it bears. However, the thinnest aquifer meaning the weakest bearing capacity, such as in the contact section of bedrock hill where the external stress is concentrated to induce earth fissure.

- Areas having aforementioned conditions in Su-Xi-Chang region should be regarded as prone areas of earth fissure. In future work one can establish mathematical model by way of selective generalization and quantitation of viscoelastic strata, buried bedrock hill and aquifers so as to analyze and predict earth fissure.

\section{ACKNOWLEDGMENTS}

This study is jointly funded by the Land and Resources Survey Project of China (Nos. 121201164, 1212010641203, 1212010641204). We are grateful to Jiangsu Team of Coal Geophysical Prospecting and Surveying for 3D seismic exploration data interpretation. 


\section{REFERENCES}

Aldiss, D.T., Black, M.G., Entwisle, D.C., Page, D.P., and Terrington, R.L. (2012). Benefits of a 3D geological model for major tunneling works: an example from Farringdon, east-central London, UK. Quarterly Journal of Engineering Geology and Hydrogeology, 45, 405-414.

Chen, G.M., Wu, J.H., and He, H.S. (2004). Report on 3D seismic exploration in ground fissure disaster area, Yin Guoan country, Shitangwan town, Wuxi City, Jiangsu province. Nanjing, Jiangsu Coal Geological, Geophysical Prospecting \& Surveying Team.

Gao, Z., Zhu, Q., Ji, Y., and Chen, X. (1997). The research on the distribution feature, genetic type and countermeasure about ground fissure events. Chinese Journal of Seismology, 1, 1-10.

Heggland, R. (1998). Gas seepage as an indicator of deeper prospective reservoirs. A study based on exploration 3D seismic data. Marine and Petroleum Geology, 15, 1-9.

Hu, J.P., and Wu, S.L. (1998). Geohydrologic environment issues in Suzhou- Changzhou-Wuxi urban group. Chinese Journal of Hydrogeology \& Engineering Geology, 4, 5-7.

Jiao, X., Su, X.S., and Yu, J. (2009). Fatalness zoning of earth fissure harzard in Suzhou-Wuxi -Changzhou area. Journal of Jilin University (Earth Science Edition), 39(1), 141-146.

Li, X.Y., Liu, Y.J., Liu, E., Shen, F., Qi, L., and Qu, S.L. (2003). Fracture detection using land 3D seismic data from the Yellow River Delta, China. The Leading Edge, 22, 680-683.

Ricker, N.H. (1979). Transient Waves in Visco-Elastic Media. Elsevier Scientific Publication Company, New York, USA.

Sargent, C., and Goulty, N.R. (2009). Seismic reflection survey for investigation of gypsum dissolution and subsidence at Hell Kettles, Darlington, UK. Quarterly Journal of Engineering Geology and Hydrogeology, $42,31-38$.

Wu, Z.Y., Yu, Q., and Zhang, Y. (2003). Forming Process of Earth Fissure Hazard in the Suzhou-WuxiChangzhou Area, Hydrogeology \& Engineering Geology, 31, 121-125.

Yang, B.J., Wang, B.C., and Zhang, B.J. (1990). Theory of Elastic Wave, Publishing House of Northeast Normal University, Beijing.

Yu, J., Chen, G.M., Wang, X.M., He, H.S., Xu, X.L., and Wu, J.H. (2006). Formation mechanism analysis on ground fissure based on 3D seismic exploration data in Yinguoan area. Wuxi City. Chinese Journal of Hydrogeology \& Engineering Geology, 4, 117-123.

Yu, J., Wang, X.M., Su, X.S., and Yu, Q. (2004). The mechanism analysis on ground fissure disaster formation in Suzhou-Wuxi-Changzhou area. Journal of Jilin University (Earth Science Edition), 34, 236241.

Zhu, Q., Gao, Z., and Guo, J. (1993). Earth fissures and their genesis analysis in Dongting, Wuxi. Chinese Journal of Seismology, 3, 31-35. 